\section{DESIGN OF A HIGH ACTIVITY AND SELECTIVITY ALCOHOL CATALYST}

Sixth Quarterly Report for Period

November 7, 1991 to February 7, 1992

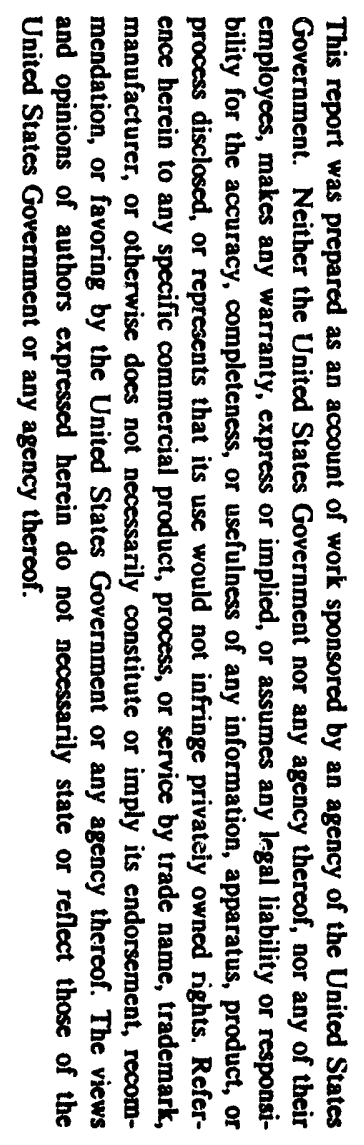

Henry C. Foley and G. Alex Mills

Coprincipal Investigators
Center for Catalytic Science and Technology
Department of Chemical Engineering
University of Delaware
Newark, Delaware 19716

Date Published:

February 7, 1992

Prepared for

Fossil Energy

Department of Energy
DE93 008 100

Under Award No. DE-FG22-90PC 90291

US/DOE Patent Clearance is not required prior to publication of this document. 
Pursuant to our goal of developing a better understanding of the methanol dehydration chemistry present in our alcohol synthesis system, we have prepared, tested, and characterized three sets of modified alumina catalysts. Furthermore, as a base case, native $\gamma-\mathrm{Al}_{2} \mathrm{O}_{3}$ was tested in our low-pressure microreactor system for methanol dehydration activity. Next, two series of $\mathrm{K}$-doped $\gamma-\mathrm{Al}_{2} \mathrm{O}_{3}$ were prepared. The first was prepared by slurrying samples of $\gamma-\mathrm{Al}_{2} \mathrm{O}_{3}$ with excess $\mathrm{KNO}_{3}$ ion-exchange solution of varying concentrations for $24 \mathrm{hr}$ at room temperature, followed by $16 \mathrm{hr}$ of calcination in air at $300^{\circ} \mathrm{C}$. The second series of $\mathrm{K}$-doped aluminas was prepared by saturating the pore volume of the alumina to incipient wetness with $\mathrm{KNO}_{3}$ solution. Again, these samples were calcined in air at $300^{\circ} \mathrm{C}$ for $16 \mathrm{hr}$.

Finally, a series of $\mathrm{K}$-doped $2.8 \% \mathrm{Rh}-3.4 \% \mathrm{Mo} / \gamma-\mathrm{Al}_{2} \mathrm{O}_{3}$ catalysts have been prepared. Here, our starting material was a bimetallic $\mathrm{Rh}-\mathrm{Mo}$ catalyst that was synthesized by sequential chemisorption of Mo and Rh carbonyls using a method described in a previous report (Fourth Quarterly Report, for period ending August 7, 1991). Samples of this bimetallic catalyst were then contacted with varying concentrations of excess $\mathrm{KNO}_{3}$ solution, stirred $24 \mathrm{hr}$ at room temperature, and once again, calcined for $16 \mathrm{hr}$ in air.

The ultimate $\mathrm{K}$ content of the materials prepared was determined by elemental analysis. Each series of samples was tested in our low-pressure microreactor for methanol dehydration activity and the results of the tests were compared to the activity of our base-case test of native $\gamma-\mathrm{Al}_{2} \mathrm{O}_{3}$. As a complement to the microreactor studies, additional characterization of the samples consisted of examining the infrared spectroscopic properties of adsorbed pyridine, as will be described below.

\section{Low-Pressure Microreactor Studies}

Samples were analyzed in a low-pressure microreactor for methanol dehydration activity. The material being tested was loaded in a Pyrex reactor tube, placed on-line with feed gas and heated in a tube furnace to reaction temperature. Methanol was delivered to the fixed bed of catalyst by passing a He carrier gas through a methanol bubbler located upstream of the reactor. The saturated $\mathrm{He} /$ methanol vapor mixture was then fed to the reactor. Downstream effluent was analyzed by gas chromatography using a flame ionization detector. The reaction conditions listed below for native $\gamma-\mathrm{Al}_{2} \mathrm{O}_{3}$ are representative of those employed while testing all the samples discussed herein. 
Reactor Temperature:

Catalyst Weight:

Mesh Size:

He Carrier Gas Feed Rate:

Bubbler Temperature: $180^{\circ} \mathrm{C}$

$0.5 \mathrm{~g}$

$60 \times 100(\sim 200 \mu \mathrm{m}$ in diameter $)$

$50 \mathrm{sccm}$

$10^{\circ} \mathrm{C}$

In addition to the conditions above, the transition-metal loaded samples were reduced prior to the introduction of the methanol feed for $4 \mathrm{hr}$ in excess $\mathrm{H}_{2}$ at $300{ }^{\circ} \mathrm{C}$. The salient reactor components used in our low-pressure (approximately atmospheric) reactor are shown in Figure 1.

Figure 2 illustrates the influence of doping the $\gamma-\mathrm{Al}_{2} \mathrm{O}_{3}$ surface with $\mathrm{K}$ by confirming that as the $\mathrm{K}$ loading increases on the surface of the samples, the conversion of methanol to dimethyl ether (DME) (the expected dehydration product) drops considerably. The second key feature of Figure 2 is the magnitude of potassium loading. The loading of $\mathrm{K}$ reflected in Figure 3, in contrast to the samples indicated in Figure 2, is considerably lower. Figure 3 depicts the conversion of methanol as a function of Kdoping on the Rh-Mo bimetallic catalyst. With regard to the mag tude of $\mathrm{K}$ loading, when compared to native $\gamma-\mathrm{Al}_{2} \mathrm{O}_{3}$, significantly less potassium has been deposited on the surface of the bimetallic catalyst. Here, we would argue that this is evidence that the process of sequentially adsorbing the Mo and Rh on the alumina, has titrated much of the latent acidity of the alumina that would otherwise have been available for ion exchange with the $\mathrm{K}^{+}$cations. Also, while Figure 3 does not depict a convincing trend in the effect of $\mathrm{K}$-doping on the bimetallic Rh-Mo catalyst, the magnitude of the conversion of methanol on these samples is nearly an order of magnitude greater than that on the bare alumina.

The apparent disparity in the level of the conversion of methanol on the Rh-Mo catalysts as compared to the native alumina can be resolved by recognizing the presence of an additional methanol decomposition pathway on the Rh-Mo catalysts. Namely, the methanol can interact with the active metal phase on these materials, perhaps by dissociatively adsorbing on the metals and subsequently breaking down into other $\mathrm{C}_{1}$ products as well as recombining into light alkanes and olefins. Figures 4 and 5 lend support to this hypothesis. Figure 4 depicts the yield of DME (as opposed to the conversion of methanol) from the same set of reactor test shown in Figure 3. When considered in combination, Figures 3 and 4 indicated that while 30 to $50 \%$ of the methanol fed to the reactor is reacted, only a small fraction is converted to methanol's expected dehydration product, DME. Additional gas chromatographic evidence for the 
formation of light hydrocarbons from the methanol was evident in that the flame ionization detector did, indeed, detect light hydrocarbons in the reactor effluent. Finally, Figure 5 presents independent evidence of the dual pathway for methanol decomposition. This figure present results for a set of experiments wherein: (i) methanol was fed to the reactor in a He carrier gas and, separately, (ii) methanol was fed to a fresh sample in a CO carrier gas. The catalyst used in each case was supported Rh-Mo, without any $\mathrm{KNO}_{3}$ treatment. Prior to introducing the methanol feed, the catalyst had been reduced for $4 \mathrm{hr}$ at $300{ }^{\circ} \mathrm{C}$ in excess $\mathrm{H}_{2}$. The selectivity measure of DME/other products displayed for both runs indicates that with the He carrier, DME is a small fraction of the ultimate decomposition products, while, in contrast, with $\mathrm{CO}$ as the carrier gas the DME is the dominant reaction product. In the case of the $\mathrm{CO}$ carrier gas, the $\mathrm{CO}$ is preferentially adsorbed on the active transition-metal sites of the catalyst, effectively poisoning their ability to decompose/react methanol to, say, $\mathrm{CO}, \mathrm{H}_{2}, \mathrm{CH}_{4}, \mathrm{C}_{2} \mathrm{H}_{6}$, etc.

\section{Infrared Spectroscopic Studies}

In order to obtain additional information about the nature and strength of the acid sites on the series of samples prepared during the last quarter, these samples were characterized by examining the characteristic infrared spectra in the range of 1400 to $1700 \mathrm{~cm}^{-1}$ wavenumbers of adsorbed pyridine molecules. In this work, fine, powdered samples were pressed into thin wafers, placed in an air-tight IR transmission cell and subjected to the following treatment and analysis:

1) Samples were dehydrated to $300^{\circ} \mathrm{C}$ under moderate vacuum, $10^{-2} \mathrm{Torr}$;

2) Samples were cooled to $200{ }^{\circ} \mathrm{C}$ and allowed to stabilize with regard to temperature fluctuations;

3) Background spectra were set to the sample transmission at $200{ }^{\circ} \mathrm{C}$ prior to pyridine dosing;

4) Samples were dosed with gaseous pyridine at low pressure and allowed to equilibrate with the gas-phase pyridine;

5) Spectra were collected for sample equilibrated with pyridine;

6) Finally, sample were exposed to moderate vacuum ( $3 \times 10^{-2}$ Torr) and spectra were collected at 200,250 and $300^{\circ} \mathrm{C}$ for the pyridine-dosed samples. 
The results of the IR analysis of the pyridine spectra suggest that (i) increasing the $K$ loading on the native $\gamma-\mathrm{Al}_{2} \mathrm{O}_{3}$ support reduces the Lewis acidity of the surface and (ii) the sequentially adsorbed transition metals in our system ( $\mathrm{Rh}$ an $\mathrm{Mo}$ ) ultimately titrated the residual acidity of the alumina.

The first of these conclusions is drawn from a combination of two sets of spectra, Figures 6 and 7. In Figure 6, pyridine has been adsorbed on the native alumina surface. Here, before exposing the doped surface to moderate vacuum, the spectrum contains signature peaks for both hydrogen bonded pyridine and pyridine coordinatively bonded to Lewis acid sites (hydrogen bonded pyridine at 1580 to $1600 \mathrm{~cm}^{-1}$ and pyridine coordinated with Lewis sites at $1453 \mathrm{~cm}^{-1}$ and 1600 to $1633 \mathrm{~cm}^{-1}$ ). Characteristic peaks for pyridine chemisorbed at Bronsted acid sites are notably absent, as expected for predominantly Lewis acidic $\gamma-\mathrm{Al}_{2} \mathrm{O}_{3}$. After exposing the alumina surface to moderate vacuum, the spectrum shows a marked reduction in hydrogen bonded pyridine, but the peaks for the residual Lewis acidity remain pronounced as is seen in the darker line of the figure. In contrast to spectra for bare alumina, those for $\mathrm{K}$-doped alumina, as represented by the characteristic spectra in Figure 7, show an almost complete flattening of the Lewis acid signature peaks upon exposure to moderate vacuum $\left(3 \times 10^{-2}\right.$ Torr $)$. Given that the sample associated with Figure 7 has an $11.9 \% \mathrm{~K}$ content (mass $\%$ ), the spectra in Figure 7 indicate that the presence of the $K$ has decreased the strength of the Lewis acid sites and may have reduced the total Lewis acid amount.

Perhaps the most important conclusions that can be drawn from the pyridine adsorption studies are born out by comparing the spectra for the following series of samples: (i) native $\gamma-\mathrm{Al}_{2} \mathrm{O}_{3}$, (ii) $\mathrm{Mo}$ on $\gamma-\mathrm{Al}_{2} \mathrm{O}_{3}$, and (iii) $\mathrm{Rh}-\mathrm{Mo}$ on $\gamma-\mathrm{Al}_{2} \mathrm{O}_{3}$. This series mirrors the sequence of transition-metal chemisorption occurring during the synthesis of our metal-loaded, bimetallic catalyst. The spectra for the native $\gamma-\mathrm{Al}_{2} \mathrm{O}_{3}$, which appear in Figure 6, have already been discussed (vide supra). Figure 8 displays the spectra for Mo on $\gamma-\mathrm{Al}_{2} \mathrm{O}_{3}$. Here, upon exposing the sample to moderate vacuum, the Lewis acidity remains evident. This suggests that either the process of chemisorbing the Mo does not effect the surface acid sites, or more realistically, the titration of Lewis acid sites by adsorbing Mo carbonyls from our $\mathrm{Mo}(\mathrm{CO})_{6}$ precursor is offset by the formation of Lewis acid sites at the $\mathrm{MoO}_{\mathrm{x}}$ layer ultimately formed on the surface after mild oxidation in air. Upon chemisorbing $\mathrm{Rh}$, followed again by mild oxidation in air, Lewis acidity is once again quashed, as demonstrated by the spectra in Figure 9 for pyridine adsorption on a $2.8 \% \mathrm{Rh}-3.4 \%$ Mo sample. Given that the residual acidity of the $\mathrm{Rh}-\mathrm{Mo} / \gamma-\mathrm{Al}_{2} \mathrm{O}_{3}$ sample is minimal, the process of $\mathrm{K}$ ion exchange would be expected to have little effect on the surface. In fact, these expectations are born out in Figure 10 for an ion-exchanged 
$\mathrm{Rh}-\mathrm{Mo} / \gamma-\mathrm{Al}_{2} \mathrm{O}_{3}$ sample. In this sample, only a limited quantity of $\mathrm{K}$ remained on the surface after prolonged ion-exchange treatment, and the spectra are insignificantly different from those seen in Figure 9 for the bimetallic sample before ion exchange treatment.

\section{Summary}

The results of the pyridine adsorption studies on native and $\mathrm{K}$-doped alumina provide fundamental grounding for the observed methanol dehydration activity of these samples. Both the reactor studies and the pyridine adsorption studies support the conclusion that the K-doped sample had reduced Lewis acidity. Moreover, we have demonstrated that we were able to measurably alter the acidity of the support surface by our ion exchange treatment. More significantly, when reactor results for transition-metal loaded samples are reconsidered in combination with their surface characteristics suggested by our pyridine adsorption studies, our hypothesis that $\mathrm{Rh}$ and Mo have ultimately titrated the support surface seems all the more convincing. Hence, in light of the pyridine adsorption results, the attenuation of a transition-metal based decomposition pathway for methanol on the metal-loaded samples-as seen in the reactor testing-is all the more reasonable. 


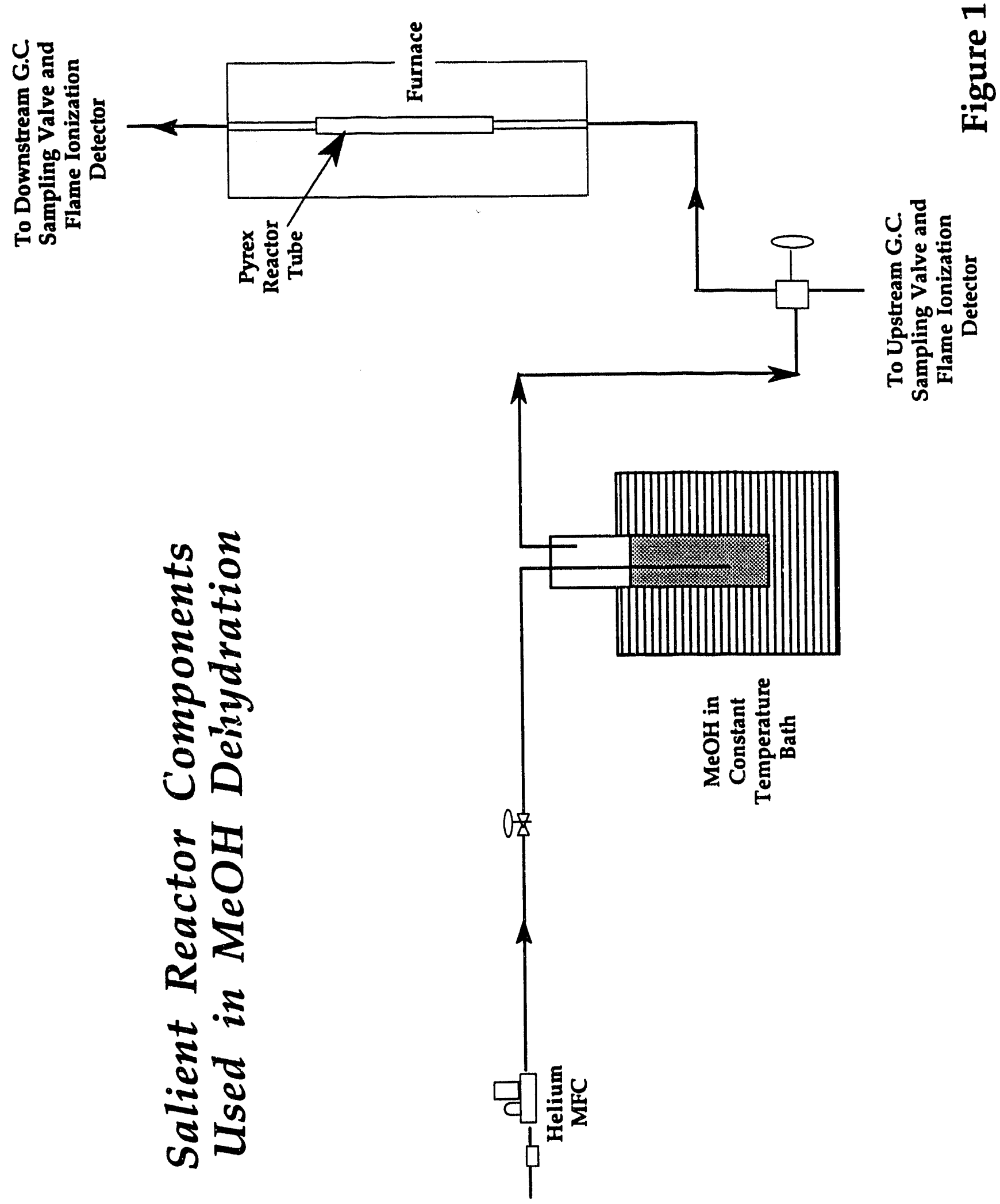




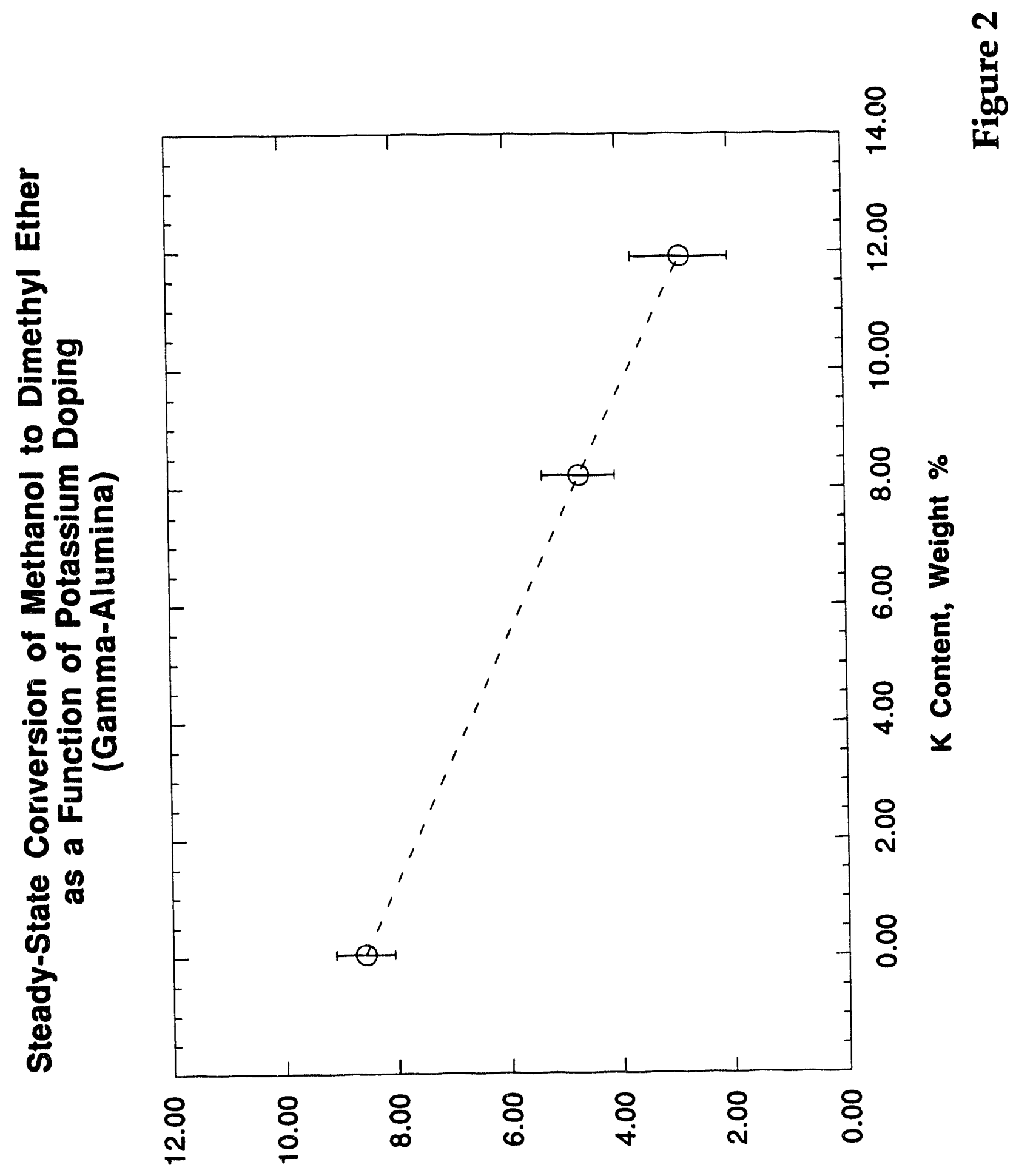

uO!sıanUOJ \% 


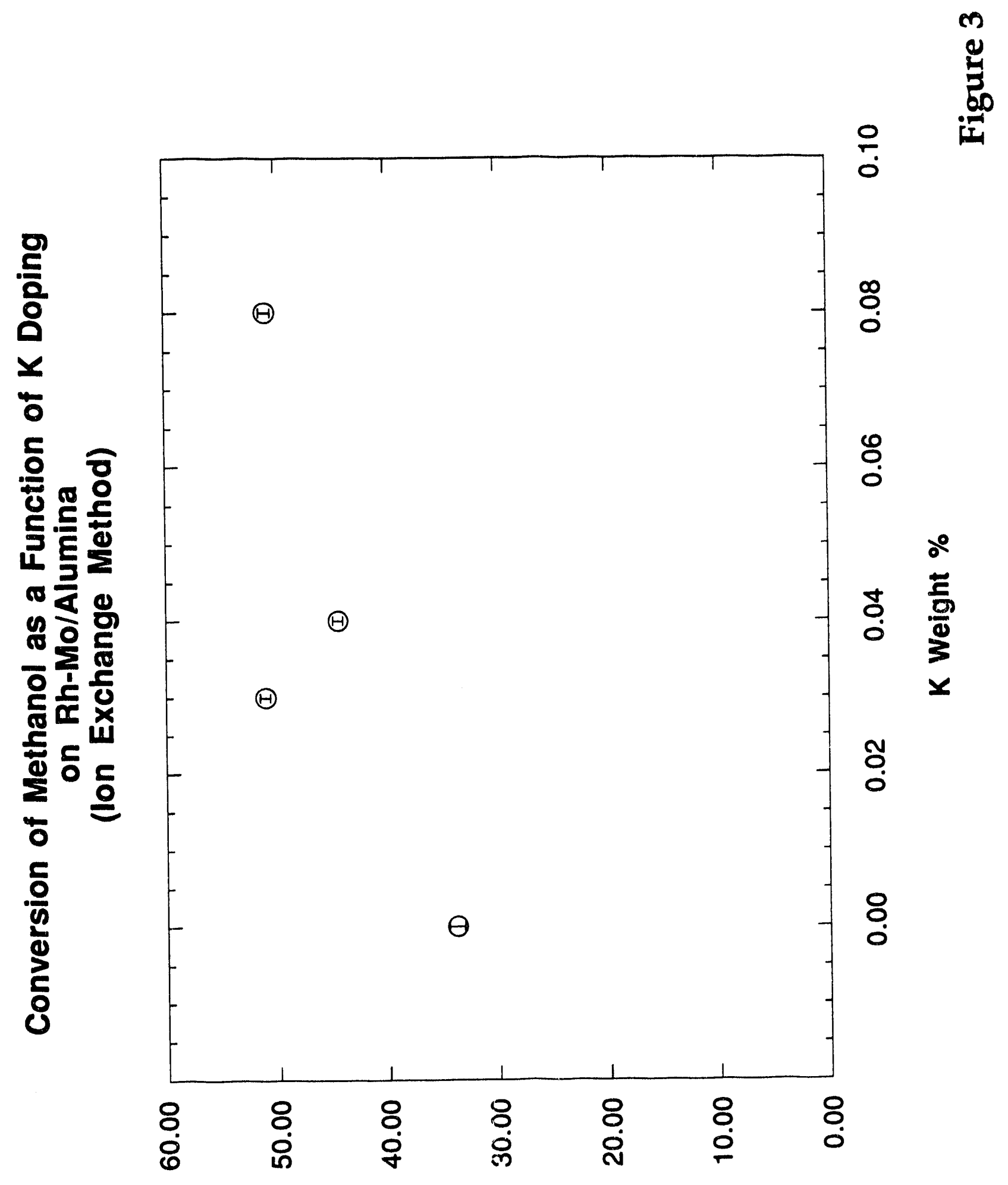




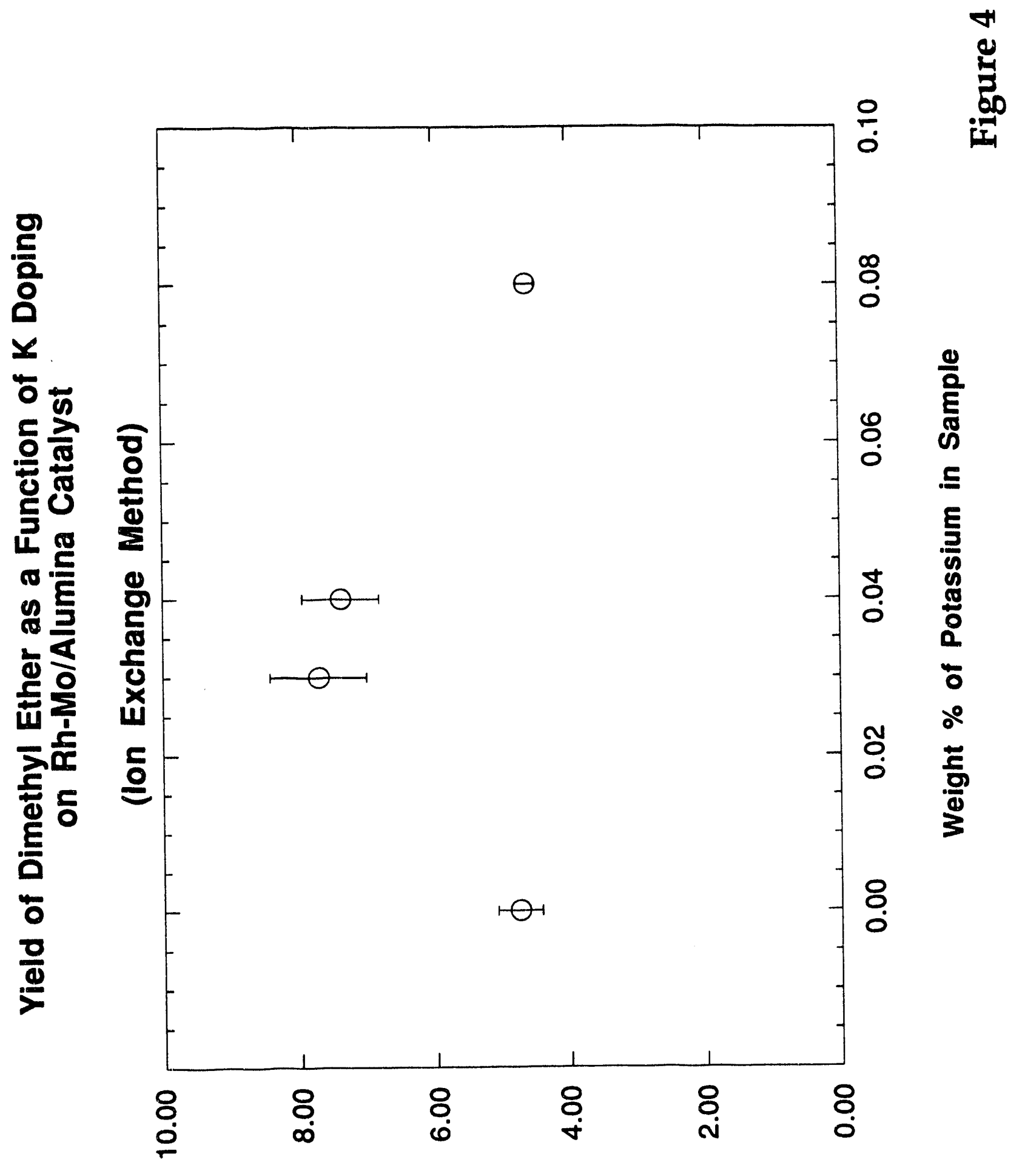

ヨwa to p|ə!ᄉ \% 


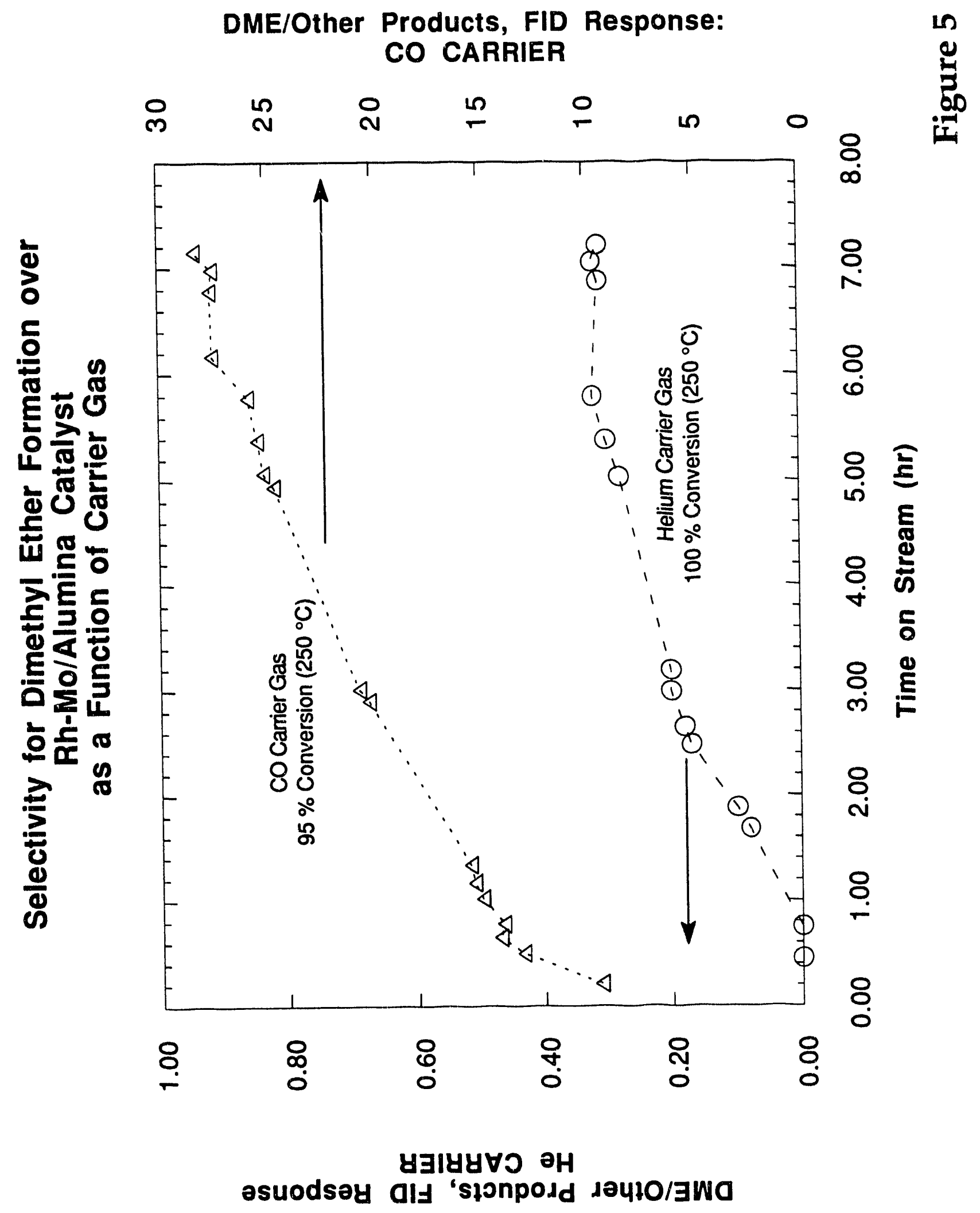




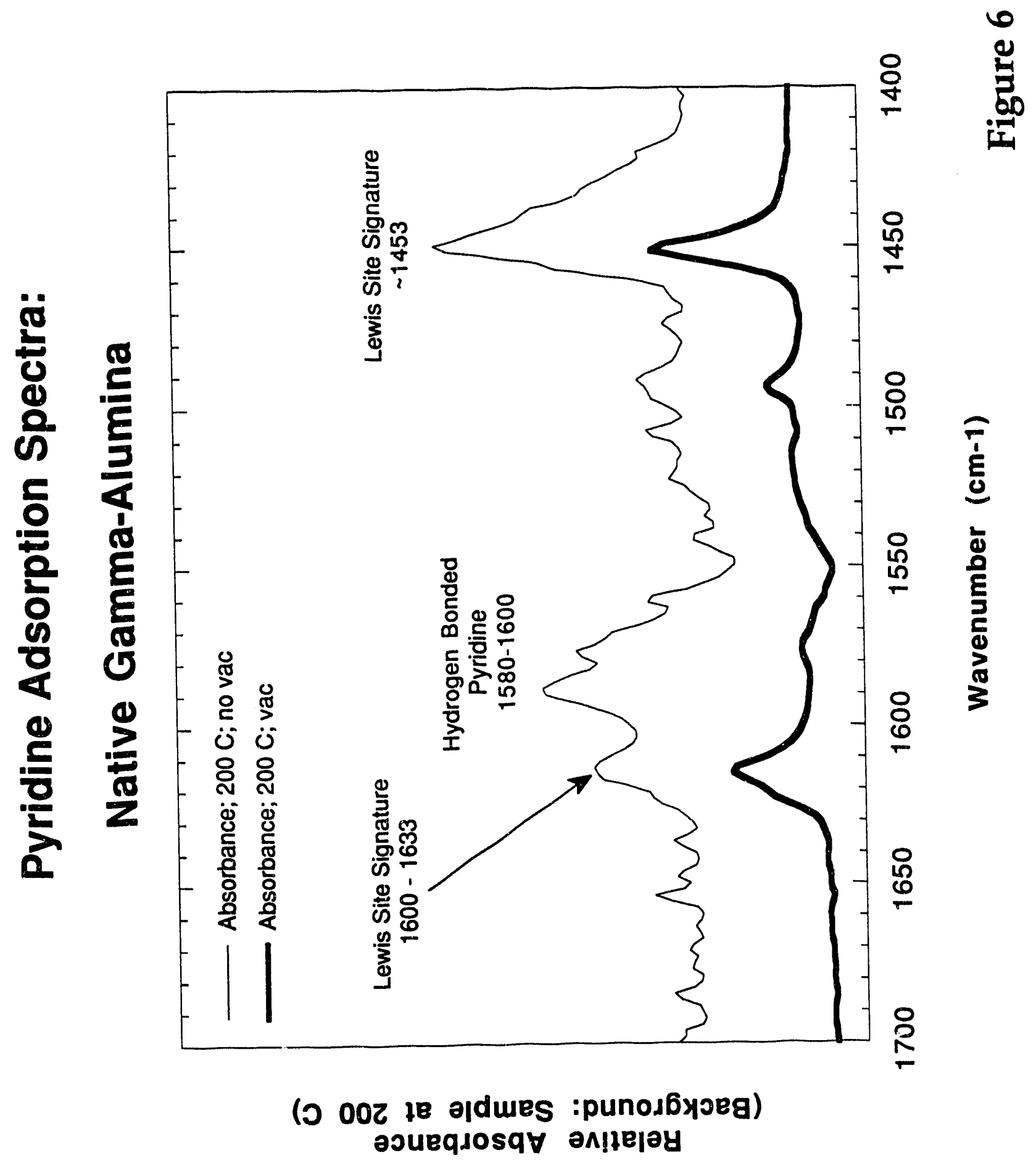




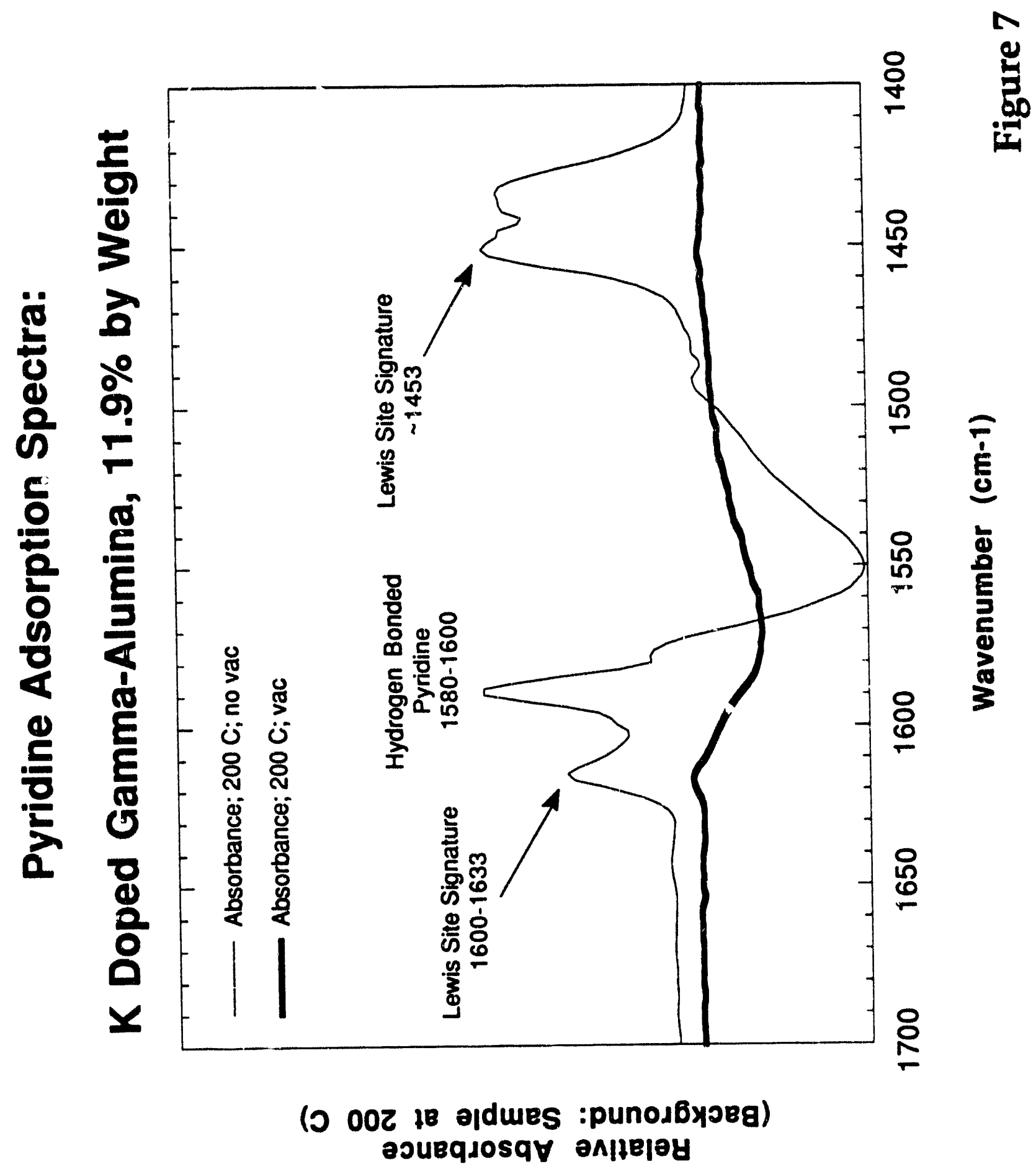




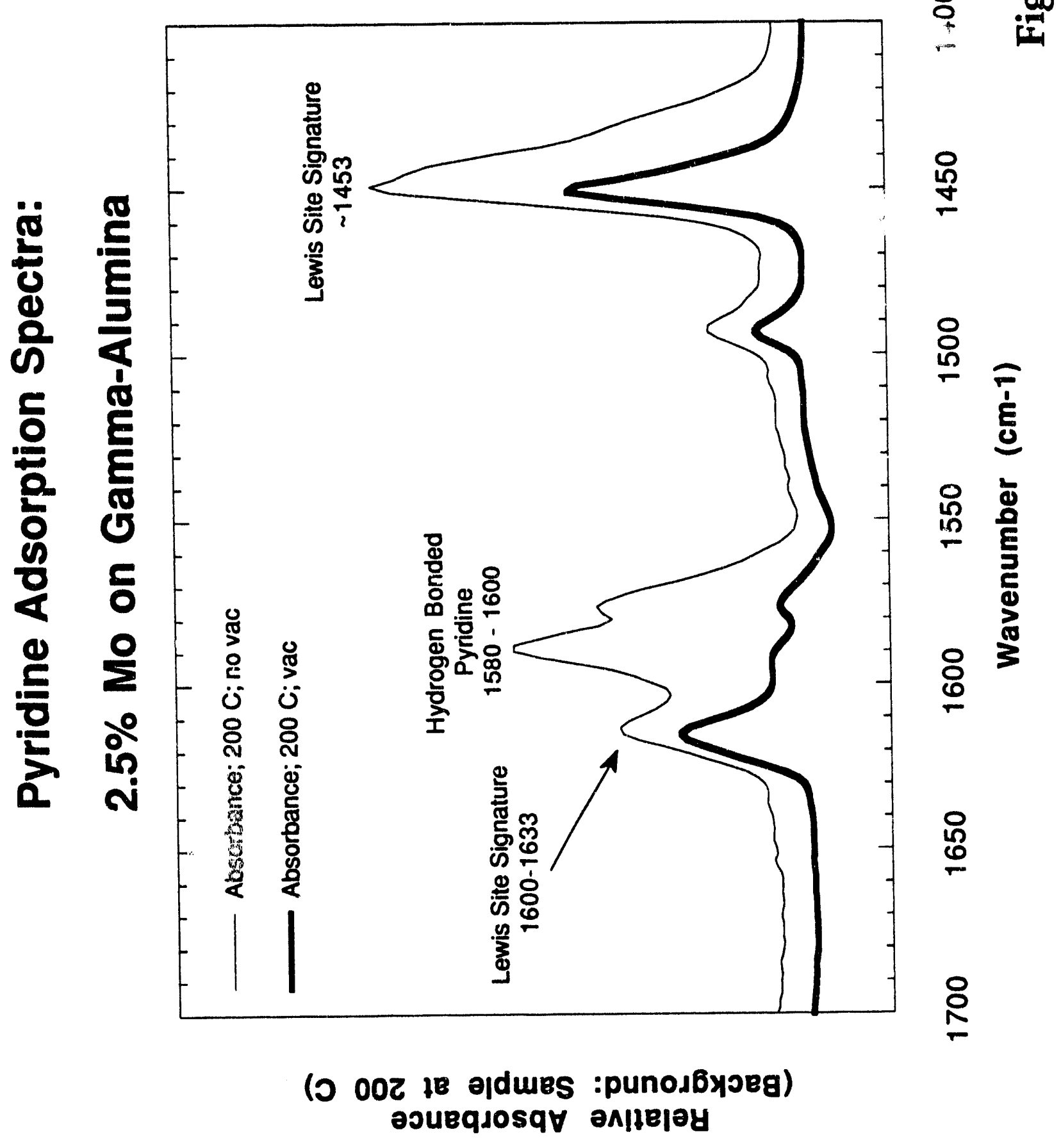




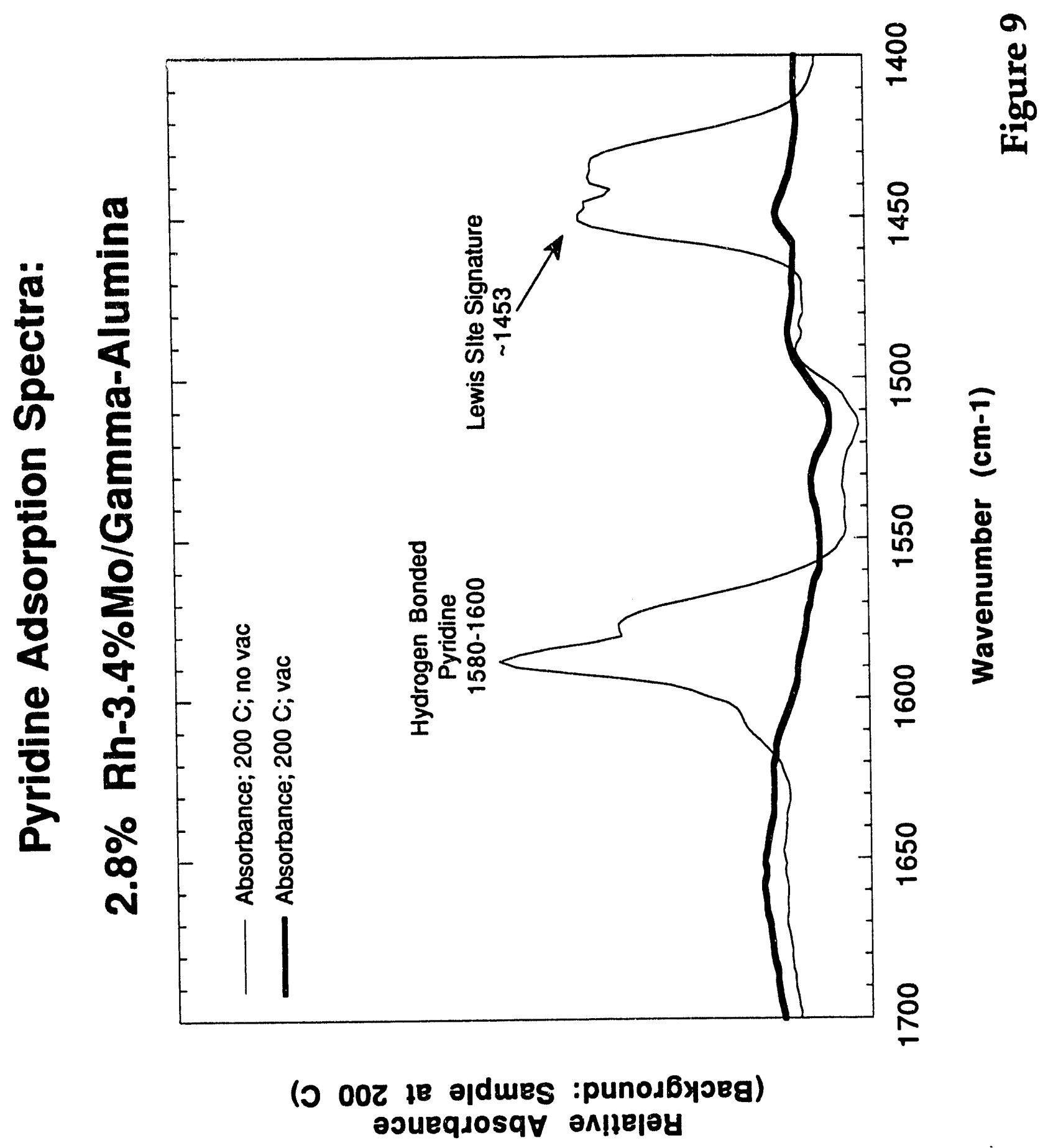




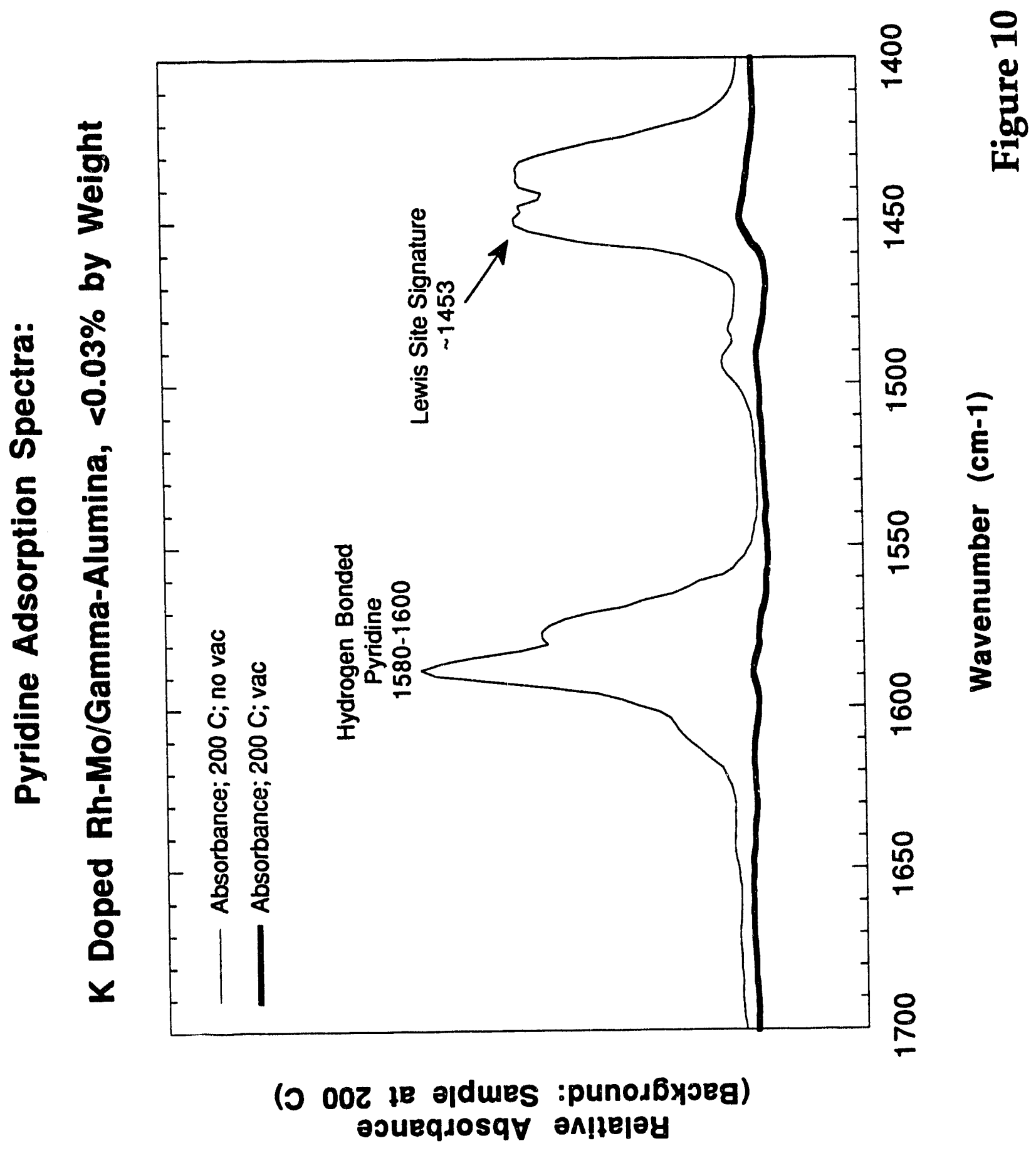



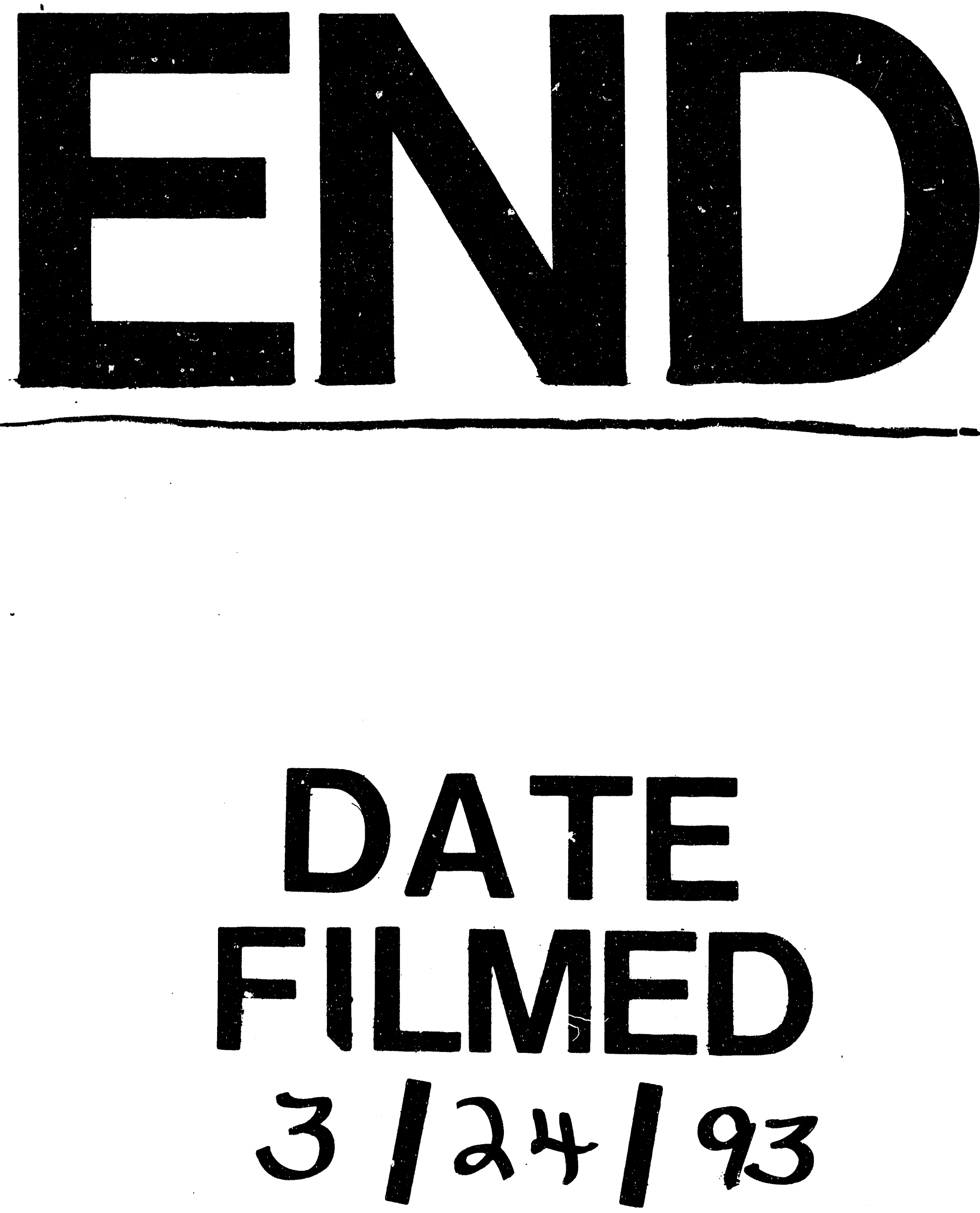
$=$ 